\title{
A State-of-Charge Based Active EV Battery Balancing Method
}

\author{
Feng Chen ${ }^{1}$, Jun Yuan ${ }^{1}$, Chaojun Zheng ${ }^{1}$, Canbo Wang ${ }^{1}$, Zhan $\mathrm{Li}^{2}$ and Xunwei Zhou ${ }^{3, *}$ \\ ${ }^{1}$ State Grid Zhejiang Electric Power Company, Ltd., Hangzhou, 310007, China \\ ${ }^{2}$ College of Electrical Engineering, Zhejiang University, Hangzhou, 310027, China \\ ${ }^{3}$ Hangzhou Xieneng Technology Co., Ltd., Hangzhou 310000, China \\ ${ }^{*}$ Corresponding author
}

\begin{abstract}
Focusing on the problem of serial cell imbalance in lithium-ion batteries applied in electric vehicles (EVs), this paper presents an active battery balancing method based on state-of-charge (SOC). The basic principle of the proposed balancing method is aligning battery cell SOCs to $50 \%$ and making sure all the cells are charged and discharges equally, so that good performance in improving capacity and anti-aging can be achieved. In this method, bidirectional Buck/Boost converters are implemented as the balancing nodes (BNs), and constitute a decentralized structure. Each individual $\mathrm{BN}$ and its control is independent, which makes the design modular, simple and flexible. The experimental results show the good performance of the proposed method in improving battery capacity and extending cycle life.
\end{abstract}

Keywords—active battery balancing; buck/boost converter; EV; state-of-charge (SOC)

\section{INTRODUCTION}

For applications in electrical vehicles (EVs), battery cells (BCs) are normally connected in series to meet the voltage and capacity requirements [1]-[2]. However, due to differences in operating conditions and internal characteristics, battery cells may suffer from imbalance problems, mainly imbalance of remaining effective capacities and state-of-charges (SOCs) [3]. Imbalance may harm the total effective capacity greatly and reduce charge-discharge life cycles. In recent years with rapid development of $\mathrm{EV}$, battery imbalance has attracted more attention and many literature focusing on this have been reported. Related surveys can be found in [4]-[5].

Balancing strategy plays an important role for balancing performance. Since there is an identified relationship between the open circuit voltage (OCV) and the SOC of the battery cell, some balancing algorithms are based on monitoring OCV [6][8]. However, a small bias in the OCV may reflects large difference of SOC, for the OCV of a cell is almost a constant in the middle SOC range. Therefore, the balancing based on monitoring SOC directly may be more beneficial and hence are preferred in many literatures [9]-[14]. These SOC-based balancing strategies normally aim to synchronize SOC of all battery cells for the maximized capacity. Whereas, with SOCsynchronized strategy the balancing execution is always needed to synchronize SOCs of batter cells with different capacities, which tends to worsen efficiency and speed up aging.
In addition, there are many discussions about the active balancing circuits. The most popular kinds are capacitor-based balancing circuits [15]-[16], inductor-based balancing circuits [17]-[18] and transformer-based circuits [19]-[20]. The circuit topologies can be Buck, Boost, Flyback, Buck/Boost, H-bridge and so on [21]-[23].

In order to achieve good performance in both improving battery capacity and prolonging cycle life, this paper proposes a novel 50\%SOC-aligned battery balancing strategy. All the battery cells are charged and discharges equally, and the SOCs are aligned to $50 \%$. For better flexibility and modularization, bidirectional buck/boost converters are implemented as the balancing nodes (BNs) and constitute a decentralized structure. Each individual $\mathrm{BN}$ and its control is independent, which makes the design modular, simple and flexible.

\section{BATTERY BALANCING STRATEGY}

A. Battery Imbalance

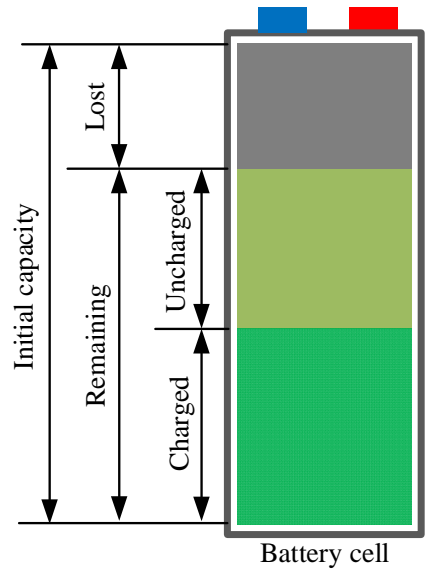

FIGURE I. DEMONSTRATION OF BATTERY CELL CAPACITY LOSS

In application, a battery pack is normally consist of a number of battery cells for higher voltage and capacity. At the very beginning, these battery cells get almost no capacity loss. However, aging leads to capacity loss as shown in Figure I. What's worse, due to the internal differences (like selfdischarge differences) and external difference (like temperature), more and more variance in capacity loss and SOC will appear to battery cells in the same pack, as shown in 
Figure II. The imbalance will reduce the total effective capacity and aggravate the differentiation and aging.

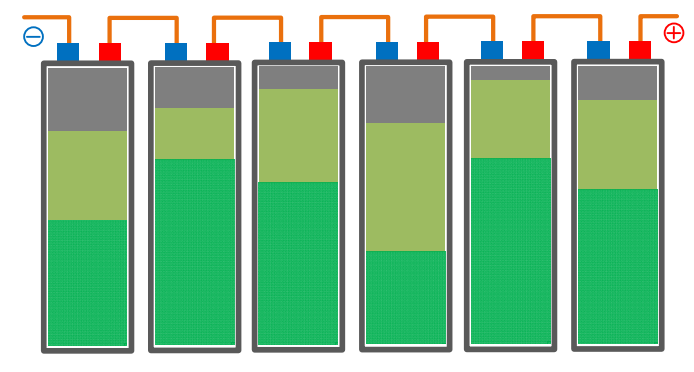

FIGURE II. BATTERY PACK WITH CAPACITY LOSS AND IMBALANCE

For better description, the remaining effective capacity and SOC of the battery cell $k$ are defined as $\mathrm{Q}_{k}$ and $\mathrm{SOC}_{k}$, and the total remaining effective capacity and SOC of the battery pack as $\mathrm{Q}_{\text {tot }}$ and $\mathrm{SOC}_{\text {tot }}$.

\section{B. Battery Balancing Strategy}
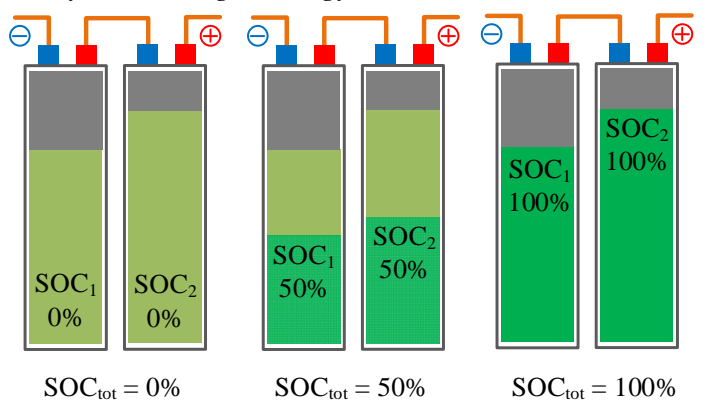

FIGURE III. DEMONSTRATION OF PREVIOUS SOC-SYNCHRONIZED BALANCING STRATEGY

Figure III shows the demonstration of previous SOCsynchronized balancing strategy. The SOCs of all battery cells are always kept at the same level. All the battery cells are synchronously charged and discharged. This strategy is able to maximize the total effective capacity. However, in order to synchronize all the SOCs, the balancing execution is always needed, which reduces battery efficiency. When SOCs are equalized, battery cells with different capacities hold different electric charges, which means the cells with less capacity are supposed to go through more energy transfer (charged and discharged by balancing nodes) in a charge-discharge cycle. This will speed up the aging of the cells with less capacity and aggregate the cells imbalance.

Unlike the SOC-synchronized strategy, the 50\%SOCaligned strategy does not equalize the SOCs all the time. The SOCs of each cell may be different in a charge-discharge cycle. But they are balanced to ensure the SOCs are symmetrical about 50\%. It can be observed in Figure IV that, after 50\% SOC aligning, the total equivalent SOC of battery pack SOC tot is consistent with the weakest battery cell. Other battery cell $\mathrm{SOC}_{k}$ is not consistent with the $\mathrm{SOC}_{\text {tot }}$, but approximately conform to a mapping relationship as shown in Figure V.

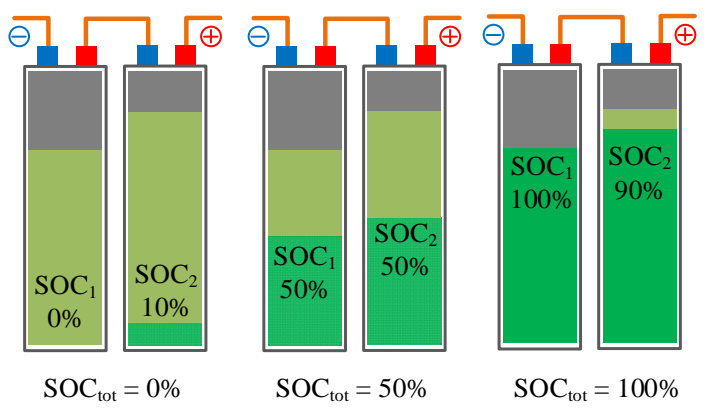

FIGURE IV. DEMONSTRATION OF PROPOSED 50\%SOC-ALIGNED BALANCING STRATEGY

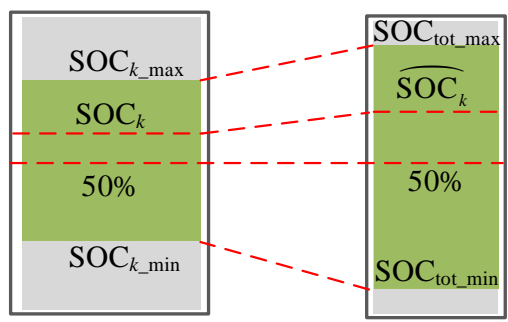

FIGURE V. DEMONSTRATION OF PROPOSED 50\%SOC-ALIGNED BALANCING STRATEGY

Assume the operation range of $\mathrm{SOC}_{\text {tot }}$ in a charge-discharge cycle as [SOC $\mathrm{SOt \_ min}_{\text {, }}, \mathrm{SOC}_{\text {tot_max }}$ ], and the operation range of $\mathrm{SOC}_{k}$ as $\left[\mathrm{SOC}_{k \_ \text {min }}, \mathrm{SOC}_{k \_ \text {max }}\right]$. Define the mapped $\mathrm{SOC}_{k}$ by the $50 \%$ SOC-aligned standard as $\widehat{\mathrm{SOC}_{k}}$, then the $\overparen{\mathrm{SOC}_{k}}$ can be calculated as (1). Consequently, only if all the mapped $\widetilde{\mathrm{SOC}_{k}}$ are equalized, all the battery cells are balanced by 50\%SOC-aligned standard.

$$
\widehat{S O C}_{k}=0.5+\left(S O C_{k}-0.5\right) \cdot \frac{S O C_{k_{-} \max }-S O C_{k_{-} \min }}{S O C_{\text {tot_max }_{-}}-S O C_{\text {tot_min }_{-}}}
$$

\section{BATTERY BALANCING CIRCUITS}

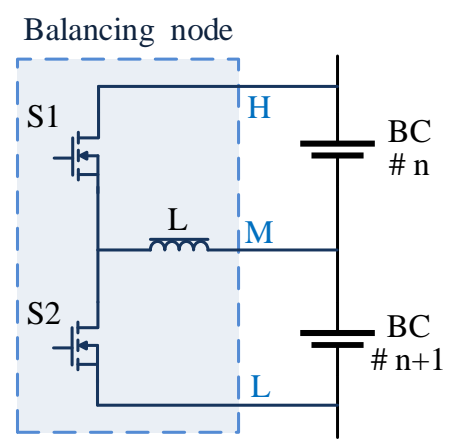

FIGURE VI. CIRCUITS OF THE BALANCING NODE.

With good flexibility and modularization capability, bidirectional Buck-Boost converter is selected as the balancing circuit topology and works as the balancing node (BN) as shown in Figure VI. A BN connects two battery cells, and transfer energy between them. The transferring direction, 
current and transferred energy are all controlled by switches S1 and S2. For example, when S2 is off and S1 operates, the energy is transferred from BC \#n to BC \#n+1.

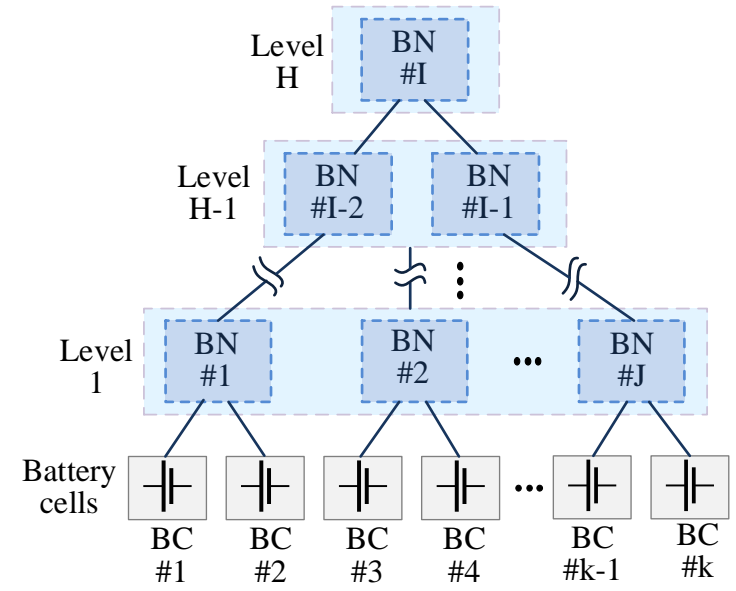

FIGURE VII. MULTILEVEL DISTRIBUTED BALANCING NODE STRUTURE FOR K CELLS.

Balancing nodes can combined to constitute a multilevel distributed balancing structure to balance more number of connected battery cells. Figure VII shows the example of $\mathrm{K}$ battery cells. The basic rule is that, the higher level BNs are in charge of the adjacent lower level BNs. In this way, the energy can be transferred between any battery cells. Normally, for a battery pack consisting of K battery cells, $\mathrm{K}-1$ balancing nodes are needed.

\section{EXPERIMENTAL RESULTS}

Figure VIII shows the experimental setup. An EV battery pack is consist of 24 battery cells. The battery pack is designed to have output voltage of $80 \mathrm{~V}$ and capacity of $60 \mathrm{Ah}$.

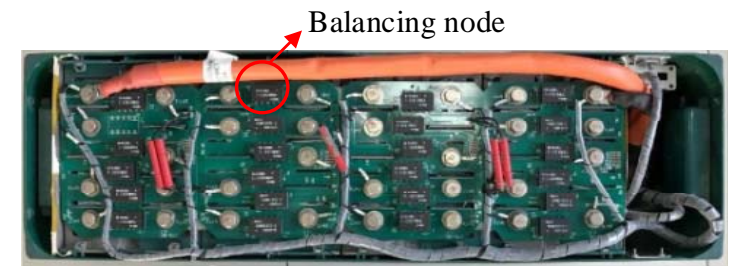

FIGURE VIII. EXPERIMENTAL SETUP: BATTERY BACK WITH 24 BATTERY CELLS

In order to verify the performance of the proposed balancing method in improving total battery capacity, experiment has been carried out on a battery pack with imbalance. The imbalanced battery cells have capacities ranging from 62Ah to 66Ah and SOCs from $45 \%$ to $90 \%$ at first. As shown in Figure IX, before the balancing system is turned on, the total effective capacity of the battery pack is only about 28Ah. Whereas, about 8 charge-discharge cycles after the balancing system is turned on, the total effective capacity goes up to 62Ah. This result shows the proposed balancing method is capable of balancing the battery well and improving battery capacity quickly.

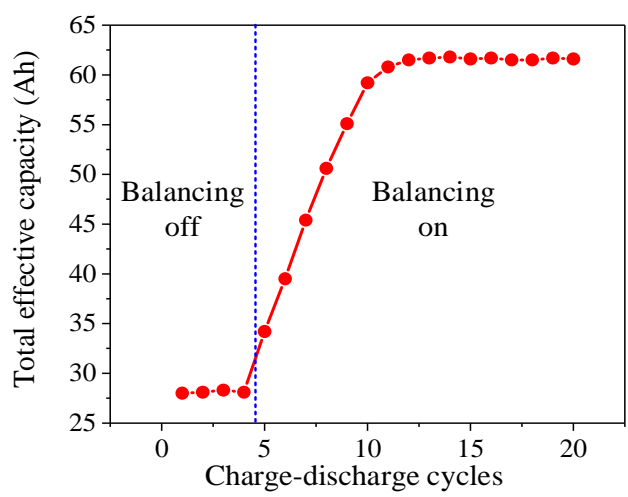

FIGURE IX. EXPERIMENTAL RESULT OF THE TOTAL EFFECTIVE CAPACITY IMPROVED BY DESIGNED BALANCING SYSTEM.

More than 2500 charge-discharge cycles are experienced to test anti-aging performance of the proposed balancing method. The result is given in Figure $X$. It shows the cycle life is extended from about 1000 to 2000 with the help of proposed balancing method (EV battery cycle life end is normally defined by $20 \%$ capacity loss). These results proves the proposed balancing method shows good performance in extending cycle life.

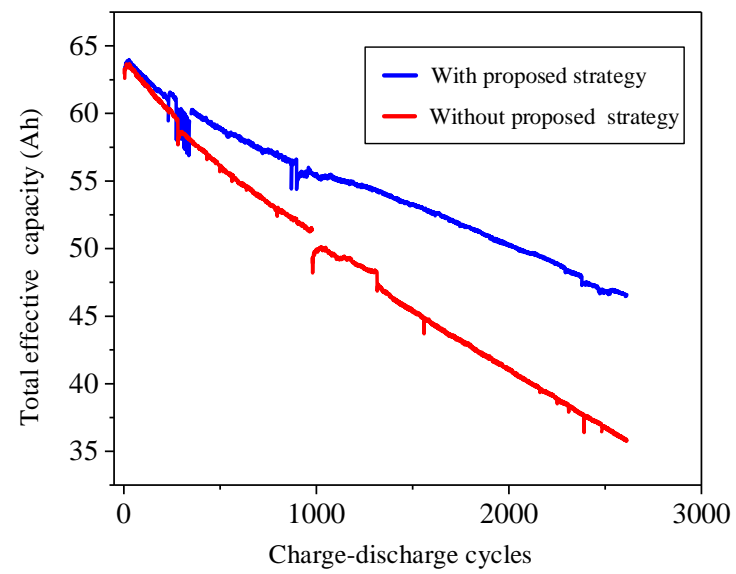

FIGURE X. CHARGE-DISCHARGE CYCLE LIFE TEST RESULTS

In conclusion, these experimental results proves this proposed balancing method is effective in improving battery capacity and extending cycle life.

\section{CONCLUSIONS}

This paper introduces a novel 50\%SOC-aligned active EV battery balancing method based on state-of-charge (SOC). The detailed balancing strategy and circuits are illustrated in this paper. Finally, the experimental results show this active balancing method is excellent in improving battery capacity and extending cycle life. In the future work, it is expected to design specific integrated circuit to accomplish node-level balancing control for better simplicity and speed, and to apply this method to more commercial EV batteries and verify the performance with wider experiments. 


\section{ACKNOWLEDGMENTS}

This work was supported by the Major Science and Technology Project of Zhejiang Province (2017C01SA1G 0113), and the Major Science and Technology Innovation Project of Hangzhou (20172011A026).

\section{REFERENCES}

[1] M. Evzelman, M. U. Rehman, K. Hathaway, R. Zane, D. Costinett, and D. Maksimovic, "Active balancing system for electric vehicles with incorporated low-voltage bus,” IEEE Trans. Power Electron., vol. 31, no. 11, pp. 7887-7895, Nov. 2016.

[2] M. Vasiladiotis and A. Rufer, "A modular multiport power electronic transformer with integrated split battery energy storage for versatile ultrafast EV charging stations,” IEEE Trans. Ind. Electron., vol. 62, no. 5, pp. 3213-3222, May 2015.

[3] S. J. Harris, D. J. Harris, and C. Li, "Failure statistics for commercial lithium ion batteries: A study of 24 pouch cells," Journal of Power Sources, vol. 342, pp. 589-597, 2017.

[4] L. Lu, X. Han, J. Li, J. Hua, and M. Ouyang, "A review on the key issues for lithium-ion battery management in electric vehicles,” J. Power Sour., vol. 226, pp. 272-288, Mar. 2013.

[5] Gallardo-Lozano J, Romero-Cadaval E, Milanes-Montero M I, Guerrero-Martinez M A. Battery equalization active methods[J]. Journal of Power Sources, 2014, 246: 934-949

[6] Y.-S. Lee and M.-W. Cheng, "Intelligent control battery equalization for series connected lithium-ion battery strings,” IEEE Trans. Ind. Electron., vol. 52, no. 5, pp. 1297-1307, Oct. 2005.

[7] N. Nguyen, S. K. Oruganti, K. Na, and F. Bien, “An adaptive backward control battery equalization system for serially connected lithium-ion battery packs,” IEEE Trans. Veh. Technol., vol. 63, no. 8, pp. 36513660, Oct. 2014

[8] S. H. Park, K. B. Park, H. S. Kim, G. W. Moon, and M. J. Youn, "Single-magnetic cell-to-cell charge equalization converter with reduced number of transformer windings," IEEE Transactions on Power Electronics, vol. 27, no. 6, pp. 2900-2911, 2012.

[9] T. Morstyn, M. Momayyezan, B. Hredzak, and V. Agelidis, "Distributed control for state of charge balancing between the modules of a reconfigurable battery energy storage system,” IEEE Trans. Power Electron., vol. 31, no. 11, pp. 7986-7995, Nov. 2016.

[10] K. M. Lee, Y. C. Chung, C. H. Sung, and B. Kang, "Active cell balancing of Li-Ion batteries using LC series resonant circuit,” IEEE Trans. Ind. Electron., vol. 62, no. 9, pp. 5491-5501, Sep. 2015.

[11] W. Huang and J. A. A. Qahouq, "Energy sharing control scheme for state-of-charge balancing of distributed battery energy storage system," IEEE Trans. Ind. Electron., vol. 62, no. 5, pp. 2764-2776, May 2015

[12] J. Kim, J. Shin, C. Chun, and B. Cho, "Stable configuration of a Li-Ion series battery pack based on screening process for improved voltage/SOC balancing,” IEEE Trans. Power Electron., vol. 27, no. 1, pp. 411-424, Jan. 2012.

[13] L. Y. Wang et al., "Balanced control strategies for interconnected heterogeneous battery systems,” IEEE Trans. Sustain. Energy, vol. 7, no. 1, pp. 189-199, Jan. 2016.

[14] X. Lu, K. Sun, J. M. Guerrero, J. C. Vasquez, and L. Huang, "State-ofcharge balance using adaptive droop control for distributed energy storage systems in DC microgrid applications," IEEE Trans. Ind Electron., vol. 61, no. 6, pp. 2804-2815, Jun. 2014.

[15] Y. Ye, K. W. E. Cheng, Y. C. Fong, X. Xue, and J. Lin, “Topology, modeling, and design of switched-capacitor-based cell balancing systems and their balancing exploration,” IEEE Trans. Power Electron., vol. 32, no. 6, pp. 4444-4454, Jun. 2017

[16] Y. Shang, B. Xia, F. Lu, C. Zhang, N. Cui, and C. C. Mi, “A switchedcoupling-capacitor equalizer for series-connected battery strings,” IEEE Trans. Power Electron., vol. 32, no. 10, pp. 7694-7706, Oct. 2017.

[17] P. Cassani and S. Williamson, "Feasibility analysis of a novel cell equalizer topology for plug-in hybrid electric vehicle energy-storage systems,” IEEE Trans. Veh. Technol., vol. 58, no. 8, pp. 3938-3946, Oct. 2009.

[18] P. A. Cassani and S. S. Williamson, "Design, testing, and validation of a simplified control scheme for a novel plug-in hybrid electric vehicle battery cell equalizer,” IEEE Trans. Ind. Electron., vol. 57, no. 12, pp. 3956-3962, Dec. 2010.

[19] K. M. Lee, S. W. Lee, Y. G. Choi, and B. Kang, “Active balancing of Li-Ion battery cells using transformer as energy carrier,” IEEE Trans. Ind. Electron., vol. 64, no. 2, pp. 1251-1257, Feb. 2017.

[20] Y. Chen, X. Liu, Y. Cui, J. Zou, and S. Yang, “A multiwinding transformer cell-to-cell active equalization method for lithium-ion batteries with reduced number of driving circuits,” IEEE Trans. Power Electron., vol. 31, no. 7, pp. 4916-4929, Jul. 2016.

[21] C.-H. Kim, M.-Y. Kim, Y.-D. Kim, and G.-W. Moon, “A modularized charge equalizer using battery monitoring IC for series connected Li-Ion battery strings in an electric vehicle," in Proc. of IEEE 8th International Power Electronics and ECCE Asia conference (ICPE \& ECCE), 2011, pp. 304-309.

[22] M. Einhorn,W. Roessler, and J. Fleig, "Improved performance of serially connected Li-Ion batteries with active cell balancing in electric vehicles,” IEEE Trans. Veh. Technol., vol. 60, no. 6, pp. 2448-2457, Jul. 2011.

[23] C. Moo, Y. Hsieh, and I. Tsai, "Charge equalization for series-connected batteries,” IEEE Trans. Aerosp. Electron. Syst., vol. 39, no. 2, pp. 704710, Apr. 2003. 